\title{
Mechanical Properties of Recycled Compounds of Polypropylene for Building Products
}

\author{
Glaucea Warmeling Duarte ${ }^{1}$, Marcelo Zaniboni de Pellegrin ${ }^{1}$, Jair Fiori Júnior ${ }^{1}$, André Luiz Grando Santos ${ }^{3}$, \\ Humberto Gracher Riella ${ }^{4} \&$ Márcio Antônio Fiori ${ }^{2}$ \\ ${ }^{1}$ Material Engineering Departament, Universidade do Extremo Sul Catarinense-UNESC, Criciúma, SC, Brazil \\ ${ }^{2}$ Post-Graduation Program in Environmental Science and Post-Graduation Program in Technology and \\ Management of the Innovation. Universidade Comunitária da Região de Chapecó (UNOCHAPECÓ)-Chapecó, \\ SC, Brazil \\ 3 Mechanical Engineering Departament, Universidade Comunitária da Região de Chapecó \\ (UNOCHAPECÓ)-Chapecó, SC, Brazil \\ 4 Post-Graduation Program in Chemical Engineering. Universidade Federal de Santa \\ Catarina-UFSC-Florianópolis, Santa Catarina, Brasil
}

Correspondence: Márcio Antônio Fiori, Post-Graduation Program in Environmental Science and Post-Graduation Program in Technology and Management of the Innovation. Universidade Comunitária da Região de Chapecó (UNOCHAPECÓ)-Chapecó, SC 89809-000, Brazil. E-mail: fiori@unochapeco.edu.br

Received: August 7, 2013 Accepted: September 10, 2013 Online Published: December 26, 2013

doi:10.5539/jmsr.v3n1p94 URL: http://dx.doi.org/10.5539/jmsr.v3n1p94

\begin{abstract}
The recycling of polymeric materials has been highly discussed due to economic and environmental factors. It is well known that, polypropylene can be used for many applications and, depending on the final characteristics that are necessary, they use different additives. So, this study aims to evaluate the mechanical properties of compositions containing recyclable polypropylene from different sources and with different composition and define the best composition using the maximum percentage of polypropylene with lower mechanical properties, which is a material considered difficult to incorporate in the process due to the high percentage of gas and impurities and the one with lowest cost. For the evaluation of mechanical properties, tensile and flexion tests were performed and, also, optical microscopy, which proved to be possible to use this kind of polypropylene in high percentages, since the conditions of mixture are guaranteed.
\end{abstract}

Keywords: recycling, polypropylene, mechanical properties

\section{Introduction}

Listening to someone talking about recycled plastic, people instantly associate the idea with low cost products. However, the technological development and the versatility of this material make them able to be used in many different areas.

Brazil produces daily million tons of plastic waste, which could often return to the supply chain or be transformed in new products (Mählmann, 2006). This waste is usually deposited in open air, which leads to contaminations of soil, air, water and problems for public health. These and the saturation and the difficult on finding areas to create more landfills leads to the necessity of finding new ways to decrease the amount of waste (Matto, 2010). The large amount of waste produced by society is a growing environmental problem that has to be managed in order to achieve a more sustainable society. One way to reduce waste is to recycle materials (Jansson, Möller, \& Gevert, 2003).

Unlike metals which are easily recoverable and recyclable, plastics waste increase forces governments to legislate for the limitation of such waste by introducing the concept of isofunctional recycling. Polypropylene (PP) and its compounds are the materials that use has mostly increased because of its characteristics of good stiffness, good ductility, acceptable elastic limit and an excellent chemical resistance at a relatively low price (Bahlouli, 2012). 
With recycling is possible to reduce substantially the volume of waste to be disposed or treated, and allows recovery of values of these materials that would, otherwise, be lost. Normally, recycled plastics have a difference of up to $40 \%$ on the price of virgin resin and, also, generate $70 \%$ of saving in energy (Matto, 2010).

Products made from recycled polymers are often cheap, of only moderate quality and of very simple design. Since extraction of raw material is the most environmentally affecting part of polymer production, it would be beneficial for the environment if recycled polymeric material to a greater extent could replace virgin material (Jansson, Möller, \& Gevert, 2003). Approaches to plastics recycling mainly include: (a) incinerated plastic behaves as a fuel (energy recycling — quaternary recycling); (a) cracked or depolymerized plastic returns into a petrochemical product or monomer, which will be trans- formed again into plastic (chemical recycling - tertiary recycling); (c) direct recovery without polymer modification (primary and secondary recycling) (Poulakis,1997).

For the recycled material to be accepted in the manufacture of new products there should be no loss in its mechanical properties. So it is very important to evaluate the changes during the recycling process (Mählmann, 2006).

The mechanical properties include all properties that determine the response of materials to external mechanical influences (Mano, 1991) and are characterized by how the material respond to requests applied, which may be either stress or strain. In polymers, the nature of this response depends on the chemical structure, temperature, processing time and history. The evaluation of mechanical properties can also be in static or dynamic mechanical behavior and the characterization can be reached with the rupture of the material or not (Junior, 2006).

Despite the existence of a wide range of thermoplastics, only five of them, i.e., polystyrene (PS), polyvinylchloride (PVC), polyethylene (PE), polyethylene terephthalate (PET) and PP, are responsible for the major quantity of recycled polymers. The main applications of polypropylene are in toys, shoes, house-ware components, packaging components for automobile industry, electrical cable insulation, etc. In building materials, polypropylene is used in piping systems for water supply, conduits, wheelbarrows, buckets, etc.

The PP used in recycling is originated from many kinds of products and, depending on the application, the PP has received a quantity of different additives, in order to make it suitable for the application. So, the mixture of some types of $\mathrm{PP}$ compounds can lead to materials of poor quality, without the technical specifications necessary to this material return to the production as raw material (Albuquerque, 2001).

The PP coming from caps and labels, that represents a large amount of the PP received for the recycling industry, contains a substantial quantity of silicon This kind of PP has a low cost, but is difficult to be incorporated in the processing with other kinds of $\mathrm{PP}$, due to the great quantity of impurities and gas that is released, thus decreasing the mechanical properties of the final product.

This work, in turn, was developed with the aim of studying the viability of incorporating PP from caps and labels in construction products by injection process. It was evaluated the effect of mixture between polypropylene from caps and labels (PP-A), polypropylene from other injected products (PP-B) and polypropylene from thermoformed products (PP-C) on the mechanical properties and, also, determined the composition that ensure the minimum mechanical properties for the manufacture of injected products for the construction industry with the maximum concentration of PP-A.

\section{Experimental Part}

The materials used in this study were the recycled polypropylene from caps and labels (PP-A), polypropylene from injected products (PP-B) and the polypropylene from thermoformed products (PP-C). All materials passed through a traditional process of mechanical recycling.

The polypropylene used as standard has concentrations of PP-A, PP-B and PP-C of 17.0\%, 70.0\% and 12.0\%, respectively. All materials were processed isolated in an extruder Oryzon-OZ-E-EX-L22 with L/D (ratio of length to diameter) equal to 17.0 and screw diameter of $22.0 \mathrm{~mm}$. The extruder has four controlled temperature zones and, the temperature used were $165.0^{\circ} \mathrm{C}, 170.0^{\circ} \mathrm{C}, 175.0^{\circ} \mathrm{C}$ and $180.0^{\circ} \mathrm{C}$, respectively.

The PP-A was extruded three times due to the large amount of gas released during processing. It is noteworthy that when the material is not subject to the condition of processing the gas is trapped and generates porosity, which affects the mechanical properties of finished products.

The experiments were defined with different percentage of the three kind of PP according a mixture experimental planning, which is shown in Table 1, and the mechanical tests were performed with five replicates. 
Table 1. Mixture experimental planning for different fractions of PP

\begin{tabular}{cccc}
\hline Experiment & PP-A & PP-B & PP-C \\
\hline $\mathbf{1}$ & 1 & 0 & 0 \\
$\mathbf{2}$ & 0 & 1 & 0 \\
$\mathbf{3}$ & 0 & 0 & 1 \\
$\mathbf{4}$ & 0.5 & 0.5 & 0 \\
$\mathbf{5}$ & 0.5 & 0 & 0.5 \\
$\mathbf{6}$ & 0 & 0.5 & 0.5 \\
$\mathbf{7}$ & 0.66 & 0.17 & 0.17 \\
$\mathbf{8}$ & 0.17 & 0.66 & 0.17 \\
$\mathbf{9}$ & 0.17 & 0.17 & 0.66 \\
$\mathbf{1 0}$ & 0.33 & 0.33 & 0.33 \\
\hline
\end{tabular}

For the preparation of the samples for tensile and flexion tests it was used an injector HIMACO, model LHS $150-80$, with temperature of extruder zones of $165.0^{\circ} \mathrm{C}, 175.0^{\circ} \mathrm{C}$ and $185^{\circ} \mathrm{C}$, respectively, and heating tip of $70.0 \%$. The system used for cooling the mold was water at room temperature, and the samples were confined in the mold for about 10 seconds.

The zones temperature both for extrusion and injection processes were chosen accordingly some tests made previously to improve the homogeneity of the final samples. Although the melting temperature of polypropylene is of about $130.0{ }^{\circ} \mathrm{C}$, the initial temperature used was $165.0^{\circ} \mathrm{C}$ because it is a recycled material that does not have a pure composition.

For the tensile tests was used the norm ASTM D638 was used with speed of $10.0 \mathrm{~mm} \cdot \mathrm{min}^{-1}$ and for the flexion tests a method was used where load of the system is made on three points. The test sample for the flexion is a rectangular cross section bar, which is set on two fixed supports and the loading is done through a third support, placed at an average distance between the fixed supports. The results obtained with the mechanical tests were evaluated using the software Statistica.

For testing the characteristics of the fracture in the samples of polymers, it was used a stereoscope (OLYMPUS, model SZX12) with an increase in 16 times. In the stereoscope, it was coupled a camera (SCION CORPORATION) for image capturing.

\section{Results and Discussion}

Table 2 presents the experimental matrix of response to the average results of maximum stress for all the samples from the tensile tests. The results showed that the PP-C has the higher value of maximum stress, 23.98 $\mathrm{MPa}$, followed by the PP-B and PP-A, 20.21 and 17.12 MPa, respectively, which is also shown by the stress vs. strain diagram, Figure 1 . The elasticity modulus is showed in the Table 2. The PP-C has higher values than the $\mathrm{PP}-\mathrm{B}$ and PP-A, respectively.

Other experiments, also shown in Table 2, indicate that there is an increase in the maximum stress with the addition of PP-B and PP-C to PP-A and, the addition of PP-C is the one which has the better results, due probably to its good compatibility with PP-A. Although the good results obtained with the addition of PP-B and PP-C to PP-A, it is still necessary to verify if these effects are statistically significant for property of maximum stress. 
Table 2. Experimental matrix of response for maximum stress for different fractions of PP

\begin{tabular}{lcccccc}
\hline PP-A & PP-B & PP-C & $\begin{array}{c}\text { Maximum Stress } \\
\text { (MPa) }\end{array}$ & $\begin{array}{c}\text { Std. Deviation } \\
(\mathbf{M P a})\end{array}$ & $\begin{array}{c}\text { Modulus of } \\
\text { Elasticity (GPa) }\end{array}$ & $\begin{array}{c}\text { Std. Deviation } \\
\text { (MPa) }\end{array}$ \\
\hline \multicolumn{3}{r}{ PP Standard } & 18.95 & 0.14 & 5.83 & 1.07 \\
1 & 0 & 0 & 17.12 & 1.09 & 3.97 & 0.66 \\
0 & 1 & 0 & 20.21 & 0.09 & 4.51 & 0.4 \\
0 & 0 & 1 & 23.98 & 0.18 & 4.78 & 0.05 \\
0.5 & 0.5 & 0 & 18.44 & 0.27 & 7.15 & 0.33 \\
0.5 & 0 & 0.5 & 23.19 & 0.36 & 3.32 & 0.45 \\
0 & 0.5 & 0.5 & 21.43 & 0.20 & 7.51 & 1.05 \\
0.66 & 0.17 & 0.17 & 20.22 & 1.60 & 5.22 & 1.45 \\
0.17 & 0.66 & 0.17 & 20.90 & 0.27 & 4.79 & 1.32 \\
0.17 & 0.17 & 0.66 & 23.31 & 0.09 & 7.35 & 0.93 \\
0.33 & 0.33 & 0.33 & 21.10 & 0.71 & 4.87 & 0.56 \\
\hline
\end{tabular}

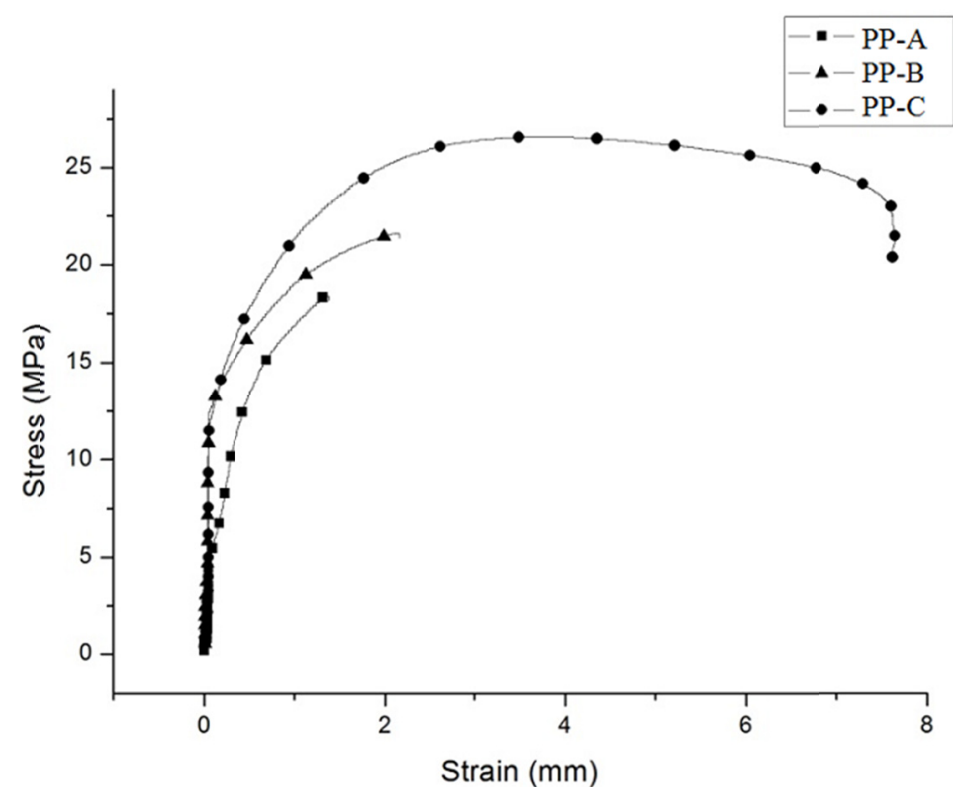

Figure 1. Stress vs. strain diagram for the three kind of PP tested

Table 3 shows the statistical analysis of variance (ANOVA) for the cubic model employed in the statistical analysis. The ANOVA shows that the model was significant with a $\mathrm{R}^{2}$ of 0.9882 and a total error of $1.0 \%$, which means a good fit of the model.

Table 3. ANOVA for the maximum stress

\begin{tabular}{llllll}
\hline & SS & df & MS & F & P \\
\hline Model $^{*}$ & 41.56168 & 6 & 6.926947 & 41.95442 & 0.005513 \\
Total Error & 0.49532 & 3 & 0.165106 & & \\
Total Adjusted & 42.05700 & 9 & 4.673000 & & \\
\hline
\end{tabular}

*Significant variables 
Table 4 presents the statistical estimated effects for the maximum stress associated with the different compositions of the mixture.

Table 4. Estimated effects for the maximum stress

\begin{tabular}{|c|c|c|c|c|c|c|}
\hline & Coeff. & Std. Error. & $\mathbf{t}(3)$ & $\mathbf{P}$ & $\begin{array}{l}-95.0 \% \\
\text { Cnf.Limt }\end{array}$ & $\begin{array}{ll}- & +95.0 \% \\
& \text { Cnf.Limt }\end{array}$ \\
\hline (A)PP-A* & 17.16140 & 0.39280 & 43.69008 & 0.000026 & 15.9113 & 18.41146 \\
\hline (B)PP-B* & 20.31595 & 0.39280 & 51.72103 & 0.000016 & 19.0659 & 21.56601 \\
\hline (C)PP-C* & 23.96868 & 0.39280 & 61.02027 & 0.000010 & 22.7186 & 25.21874 \\
\hline Interaction AB & -0.60530 & 1.97727 & -0.30613 & 0.779523 & -6.8978 & 5.68725 \\
\hline Interaction $\mathbf{A C}^{*}$ & 10.62016 & 1.97727 & 5.37113 & 0.012635 & 4.3276 & 16.91270 \\
\hline Interaction BC & -2.47075 & 1.97727 & -1.24958 & 0.300064 & -8.7633 & 3.82179 \\
\hline Interaction $\mathbf{A B C}$ & 5.07177 & 13.03548 & 0.38907 & 0.723194 & -36.4129 & 46.55647 \\
\hline
\end{tabular}

*Significant variables

This analysis shows that all independent variables (fraction of PP-A, PP-B and PP-C) and the interaction between of the fractions PP-A and PP-C (interaction AC) are positive. The statistical tests (Test $t$, Test P and Confidence Limit with 95.0\%) show that independent variables and interaction $\mathrm{AC}$ are significant.

The significance of the interaction AC can be an indication that the mixing of PP-A and PP-C has good and the compound have a good compatibility. Its good mixing compensates the deficiency in the mechanical strength of PP-A.

The mixture of PP-C, PP-A has modulus of elasticity $(3.32 \pm 0.45)$ GPa with similar magnitude of the pure PP-A which is $(3.97 \pm 0.66)$. The difference between these modules can not be considered statistically significant and is an indicative that the polymer PP-C molecules decreases the amount of failure of the polymeric matrix PP-A without impairing its mobility. Thus, increases the maximum stress without increasing the modulus of elasticity.

By results of the Table 4, one can also conclude that the polypropylene which promotes the higher effect in the mixture is PP-C, what is proved for the results of the experiment three (Table 1) where PP-C showed the higher value for maximum stress.

Figure 2 shows the results of the maximum stress for the significant variables and the PP standard, which confirms the results obtained with the statistical analysis. The maximum stress of the PP standard is higher than the PP-A, although it is lower than the other significant variables, which indicates that it is possible to combine the maximum stress of the three kind of PP in order to increase the percentage of PP-A used.

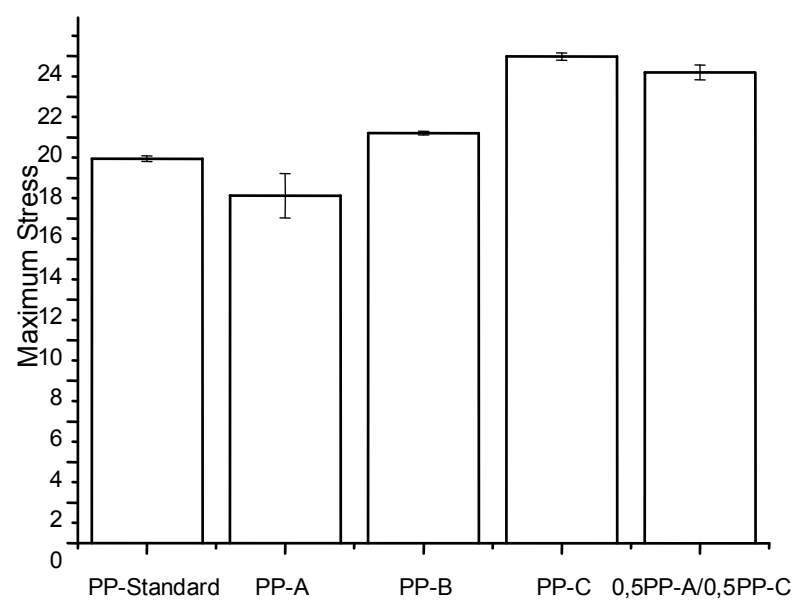

Figure 2. Tensile results for the statistical significant variables 
With the results obtained by the statistical analysis, utilizing the mixture planning methods and linear correlations methods was possible to estimate the effects and the statistical equation for maximum stress as a function of the significant variables, shown in Equation (1). This equation shows the relationship between significant variables and respectively statistical coefficients of the linear correlations. The expressions show that the PP-C is the component which most influence in the maximum stress of the total composition, due to the higher coefficient presented.

$$
\text { Maximum Stress }=(17.16 \mathrm{~A}+20.32 \mathrm{~B}+23.97 \mathrm{C})( \pm 0.39)+10.62( \pm 1.98) \text { A.C }
$$

All the possible compositions to be used can be seen in the diagram, Figure 3.

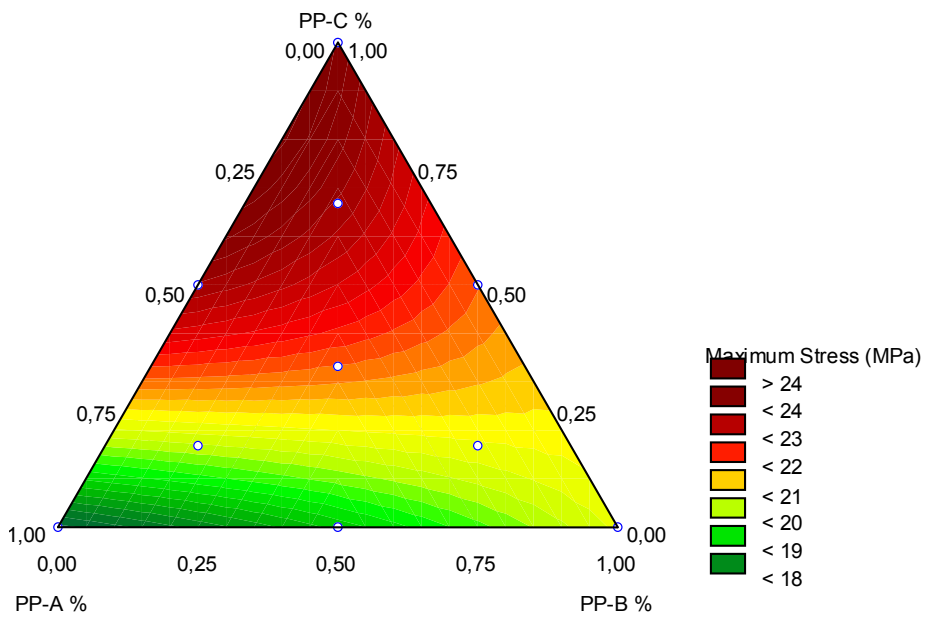

Figure 3. Diagram for maximum stress responses

The results indicate possibility of maximum stress values exceeding 24.0 MPa and lower than 18.0 MPa. As the maximum stress for the PP standard is about $19.0 \mathrm{MPa}$ (Table 2) it is possible to conclude that, all concentrations situated above the yellow band can be considered. So, it is possible the use of up to about $75.0 \%$, what is a great advance when compared to the $17.0 \%$ that is used in the PP standard.

Table 5 shows the matrix of response for flexural strength and strain. The PP-B and PP-C have the maximum strain, 40.04 and $28.82 \mathrm{~mm}$, respectively, which is an indicative of the good homogeneity of these materials, which are considered noble materials in the recycling industries. The comparison with the PP standard shows that only PP-C has flexion characteristics suitable for pure application, i.e., flexural strength and strain higher than the PP standard. The Figure 4 shows the diagram of flexural strength vs. strain for the three kind of pure PP, what confirms the media results of Table 5.

Table 5. Experimental matrix of responses for the flexion test for different fractions of PP

\begin{tabular}{|c|c|c|c|c|c|c|}
\hline PP-A & PP-B & PP-C & $\begin{array}{c}\text { Flexural Strength } \\
\text { (kgf) }\end{array}$ & $\begin{array}{c}\text { Std. } \\
\text { Deviation }\end{array}$ & $\begin{array}{l}\text { Strain } \\
(\mathrm{mm})\end{array}$ & $\begin{array}{c}\text { Std. } \\
\text { Deviation }\end{array}$ \\
\hline \multicolumn{3}{|c|}{ PP - Standard } & 5.63 & 0.19 & 26.78 & 0.84 \\
\hline 1 & 0 & 0 & 5.55 & 0.15 & 20.01 & 1.98 \\
\hline 0 & 1 & 0 & 5.21 & 0.14 & 40.04 & 0.02 \\
\hline 0 & 0 & 1 & 6.97 & 0.21 & 28.82 & 1.53 \\
\hline 0.5 & 0.5 & 0 & 5.55 & 0.14 & 40.03 & 0.02 \\
\hline 0.5 & 0 & 0.5 & 6.36 & 0.32 & 29.37 & 3.28 \\
\hline 0 & 0.5 & 0.5 & 6.02 & 0.37 & 28.92 & 1.29 \\
\hline 0.66 & 0.17 & 0.17 & 5.75 & 0.10 & 28.66 & 1.61 \\
\hline 0.17 & 0.66 & 0.17 & 6.17 & 0.38 & 29.26 & 1.96 \\
\hline 0.17 & 0.17 & 0.66 & 6.52 & 0.18 & 28.97 & 1.55 \\
\hline 0.33 & 0.33 & 0.33 & 6.35 & 0.32 & 27.31 & 0.69 \\
\hline
\end{tabular}


These results also indicates that the value of flexural strength is not affected with the addition of PP-B to PP-A, although the flexural strain is significantly increased. The addition of PP-C to PP-A increases both flexural strength and strain. Although the good results obtained with the addition of PP-B and PP-C to PP-A, it is still necessary to verify if these effects are statistically significant for properties of flexural strength and strain.

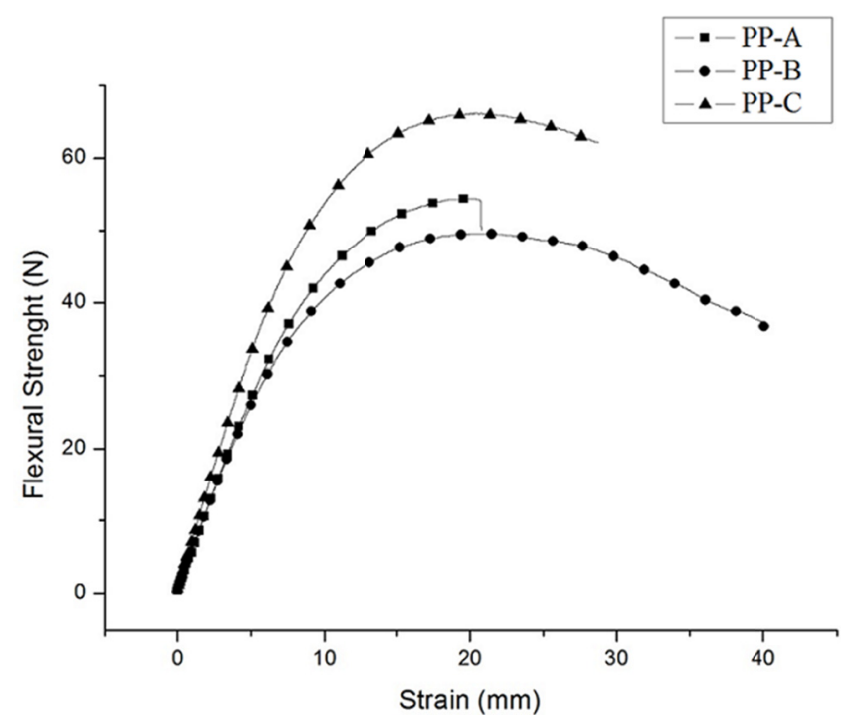

Figure 4. Diagram flexural strength vs. strain for the flexion test

Table 6 shows the analysis of variance (ANOVA) for flexural strength. It was used the cubic model the statistical treatment results, which provide a $\mathrm{R}^{2}$ of 0.9261 , indicating a good fit by the cubic model. ANOVA shows that the model is not significant, although by the value of $\mathrm{R}^{2}$ and total error, which is of only of about $7.0 \%$, it is possible to conclude that it is not relevant.

Table 6. ANOVA for flexural strength

\begin{tabular}{cccccc}
\hline & SS & df & MS & F & P \\
\hline Model & 2.374595 & 6 & 0.395766 & 6.266914 & 0.080286 \\
Total Error & 0.189455 & 3 & 0.063152 & & \\
Total Adjusted & 2.564050 & 9 & 0.284894 & &
\end{tabular}

*Significant variables

Table 7 present the estimated effects for flexural strength.

Table 7. Matrix of estimated effect for the flexural strength for different fractions of PP

\begin{tabular}{ccccccc}
\hline & Coeff. & Std.Err. & $\mathbf{t ( 3 )}$ & P & $\begin{array}{c}-\mathbf{9 5 . 0 \%}- \\
\text { Cnf.Limt }\end{array}$ & $\begin{array}{c}+95.0 \%- \\
\text { Cnf.Limt }\end{array}$ \\
\hline (A)PP-A* & 5.477995 & 0.242929 & 22.54974 & 0.000191 & 4.7049 & 6.25110 \\
(B)PP-B* & 5.314358 & 0.242929 & 21.87614 & 0.000209 & 4.5412 & 6.08747 \\
(C)PP-C* & 6.936177 & 0.242929 & 28.55223 & 0.000094 & 6.1631 & 7.70929 \\
Interaction AB & 0.744706 & 1.222856 & 0.60899 & 0.585550 & -3.1470 & 4.63638 \\
Interaction AC & 0.188342 & 1.222856 & 0.15402 & 0.887373 & -3.7033 & 4.08002 \\
Interaction BC & -0.138930 & 1.222856 & -0.11361 & 0.916722 & -4.0306 & 3.75274 \\
Interaction ABC & 9.391760 & 8.061894 & 1.16496 & 0.328247 & -16.2648 & 35.04830 \\
\hline
\end{tabular}

*Significant variables 
The analysis shows too that all independent variables are significant and with a positive effects, indicating that the increase in the percentage of any of the components cause an increase in the flexural strength. The positive effect indicates that the addition of PP-B and PP-C offsets the low flexural strength of PP-A. This effect is higher for PP-C, what is in agreement with the results obtained in Table 4 and to the fact that PP-C is considered, in the recycling industries, a noble material, with good mechanical properties.

With the results obtained by the statistical analysis of the estimated effects it is possible to obtain the equation for flexural strength as a function of the significant variables, shown in Equation (2). This equation shows that the PP-C is the component which most influence in the maximum stress of the total composition, due to the higher coefficient presented.

$$
\text { Flexural Strength }=(5.48 \mathrm{~A}+5.31 \mathrm{~B}+6.94 \mathrm{C})( \pm 0.24)
$$

The Figure 5 shows the dependence of flexural strength with the percentage of all polypropylene testes. The results indicate the possibility of flexion forces between $6.8 \mathrm{kgf}$ and $5.4 \mathrm{kgf}$. As the flexural strength for the PP standard is about $5.63 \mathrm{kgf}$ (Table 5) it is possible to conclude that, all concentrations situated above the light green band can be considered. So, it is possible the use of up to about $75.0 \%$ of PP-A.

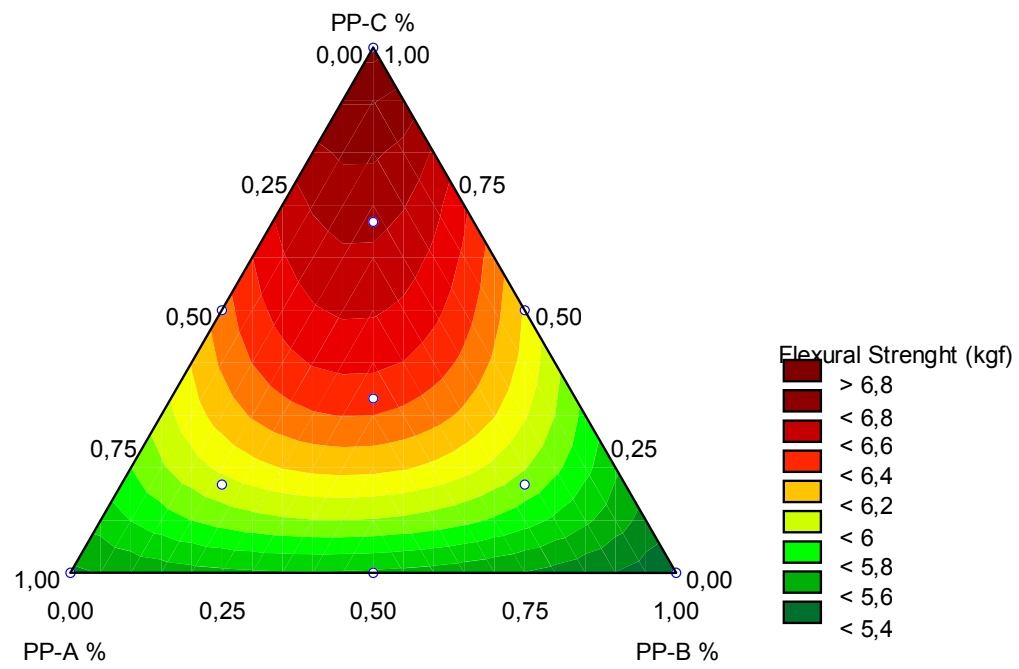

Figure 5. Diagram for flexural strength

Tables 8 and 9 show the ANOVA and estimated effects for the response of strain. It was used the cubic model for the statistical treatment, which provide a $\mathrm{R}^{2}$ of 0.9245 , indicating a good fit by the cubic model. Although ANOVA shows that the model is not significant, the high value of $\mathrm{R}^{2}$ and low total error (about $7.5 \%$ ) it is possible to conclude that it is not relevant. The results of the estimated effect showed that all kinds of polypropylene are significant and with a positive effect. As well as for the other properties that were already discussed before, the positive effect indicates that the addition of PP-B and PP-C offsets the low strain of PP-A. In this case the higher effects if obtained for PP-B, what is in agreement with the results obtained in Table 5, in which PP-B had the higher value for strain response.

Table 8. ANOVA for strain

\begin{tabular}{cccccc}
\hline & SS & df & MS & F & P \\
\hline Model & 290.7885 & 6 & 48.46475 & 6.120305 & 0.082798 \\
Total Error & 23.7560 & 3 & 7.91868 & & \\
Total Adjusted & 314.5445 & 9 & 34.94939 & & \\
\hline
\end{tabular}


Table 9. Estimated Effects for Strain

\begin{tabular}{|c|c|c|c|c|c|c|}
\hline & Coeff. & Std.Err. & $t(3)$ & $\mathbf{P}$ & $\begin{array}{l}-95.0 \% \\
\text { Cnf.Limt }\end{array}$ & $\begin{array}{ll}+95.0 \% \\
\text { Cnf.Limt }\end{array}$ \\
\hline (A)PP-A* & 20.405 & 2.72028 & 7.50101 & 0.004909 & 11.748 & 29.0620 \\
\hline (B)PP-B* & 38.816 & 2.72028 & 14.26902 & 0.000746 & 30.159 & 47.4730 \\
\hline (C)PP-C* & 29.506 & 2.72028 & 10.84659 & 0.001677 & 20.849 & 38.1630 \\
\hline Interaction $\mathbf{A B}$ & 38.349 & 13.69334 & 2.80059 & 0.067820 & -5.229 & 81.9277 \\
\hline Interaction AC & 21.969 & 13.69334 & 1.60438 & 0.206969 & -21.609 & 65.5477 \\
\hline Interaction BC & -23.117 & 13.69334 & -1.68818 & 0.189960 & -66.695 & 20.4615 \\
\hline Interaction $\mathbf{A B C}$ & -184.642 & 90.27578 & -2.04531 & 0.133364 & -471.940 & 102.6560 \\
\hline
\end{tabular}

*Significant variables

With the results obtained by the statistical analysis of the estimated effects it is possible to obtain the equation for flexural strain as a function of the significant variables, shown in Equation (3). This equation shows that the $\mathrm{PP}-\mathrm{B}$ is the component which most influence in the maximum stress of the total composition, due to the higher coefficient presented.

$$
\text { Strain }=(20.40 \mathrm{~A}+38.82 \mathrm{~B}+29.51 \mathrm{C})( \pm 2.72)
$$

The Figure 6 shows the dependence of flexion strain with the percentage of all polypropylene testes. The results indicate the possibility of flexion strain between 24.0 and $40.0 \mathrm{~mm}$.

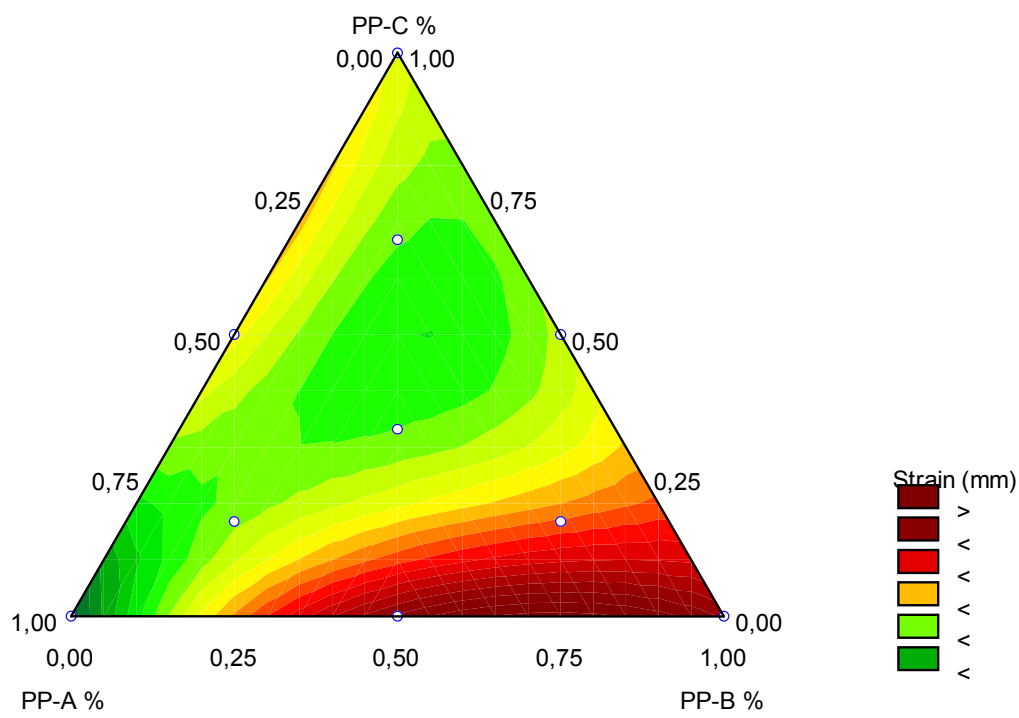

Figure 6. Diagram for the flexural strain

As the flexural strain for the PP standard is about $26.78 \mathrm{~mm}$ (Table 5) it is possible to conclude that, concentrations situated in the light green, yellow and red bands can be considered. So, it is possible the use a great range of compositions. The maximum percentage of PP-A is of about $70.0 \%$.

Figure 7 show a diagram with the comparison of the flexion results (flexural strength and strain) for the significant variables in contrast with the results of PP standard. This diagram shows that, the only polypropylene with medium flexion properties is the PP-A. The other polypropylenes showed better flexion properties. 


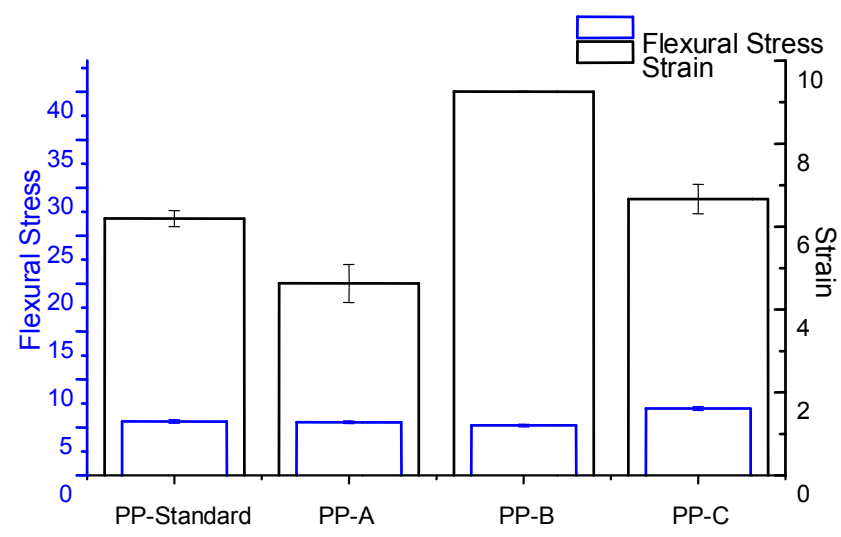

Figure 7. Flexion results for the statistical significant variables

Figure 8 shows the optical micrographs of the fracture of the samples of PP-standard, PP-A, PP-B and PP-C, respectively.
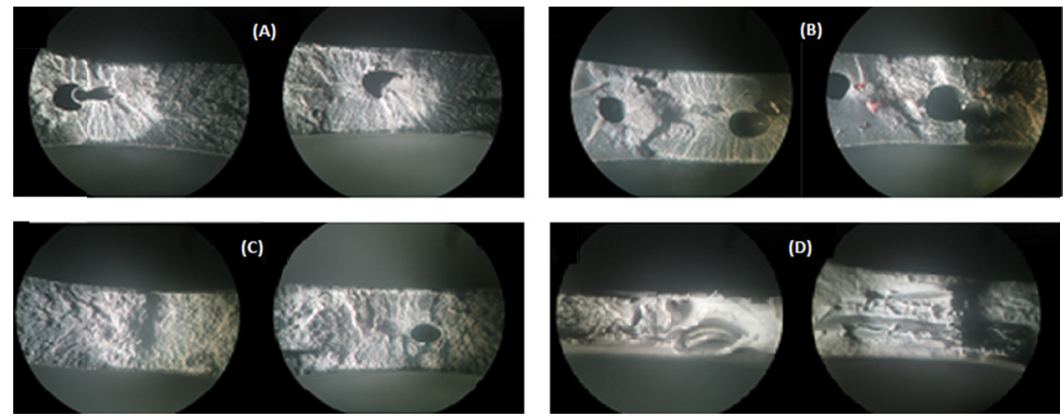

Figure 8. Micrographs (a) PP standard; (b) PP-A; (c) PP-B and (d) PP-C

Figure $8(\mathrm{~b})$ shows that the fracture of the samples of PP-A presented brittle fracture regions (dark) and ductile fractions (light) and, also, a lot of flaws present in the sample. The number and size of pores are larger than in PP-standard (a) and it can be associated with the poor mechanical properties of the material. In turn, the regions of fractures of the samples of PP-B (c) contain smaller amounts of failure and largest regions of ductile fracture. These characteristics explain the strength and deformation capacity greater than PP-A. The micrographs of PP-C (d) show the predominance of ductile fracture and much smaller flaws. These features indicate that PP-C is the material of greater mechanical strength and deformation capacity.

Figure 9 shows the optical micrographs of the fracture regions for the samples with major concentration of PP-A (66.0\% of PP-A, $17.0 \%$ of PP-B and $17.0 \%$ of PP-C), evaluated in the work. The micrographs presented characteristics of the three pure samples. The surface present pores that are characteristic of the presence of PP-A and large regions of ductile fractures that are characteristic of PP-C. In some samples there are few and small pores, characteristic of PP-C. It is important to consider that in some fracture regions there are the presences of pores and in other not. This result is strongly indicative of the lack of homogeneity of the mixture.
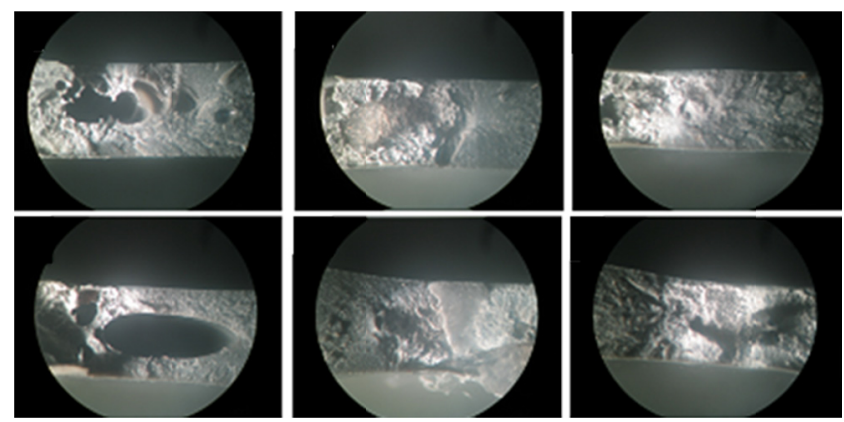

Figure 9. Micrographs of the samples with higher percentage of PP-A 
As the PP-C is considered to a material more noble than the PP-A and PP-B, one should seek to use in the compositions as much as possible the last two materials, preferably with a higher percentage of PP-A. Comparing the three diagrams (maximum strength, flexural strength and strain), showed in Figure 10, and the properties of PP standard, it is possible to conclude that the best composition of PP-A, PP-B and PP-C is of about $50.0 \%, 32.0 \%$ e $18.0 \%$, respectively, represented by X point in the Figure. Substituting these values in the statistical equations it is the expected the following results: Maximum Strength $20.4 \mathrm{MPa}$, Flexural Strength 5.7 kgf and strain $27.9 \mathrm{~mm}$.
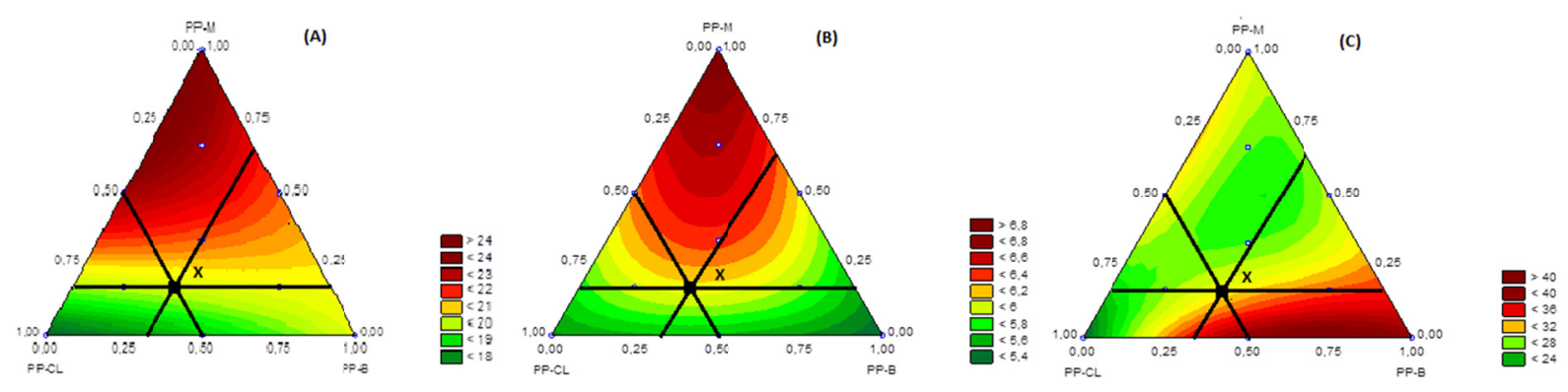

Figure 10. Comparison of diagram for the mechanical properties: (a) Maximum Stress; (b) Flexural Strength and (c) Strain

\section{Conclusions}

Among the tested polypropylene, PP-A is the one which has the worst mechanical properties, reason why this material is so cheap and undesirable in the recycling industry. PP-C is the one which has, in average, the better mechanical properties, due to its good homogeneity, for this is considered a noble material in the recycling industries.

By the statistical experimental factorial planning used it is possible to obtain a mixture with mechanical properties higher than the PP standard, that is been currently used. So the mechanical properties can be adjusted depending on the final application. The mixture chosen, which has about the same mechanical properties than PP standard and the higher possible amount of PP-A, has the following composition: 50.0\% PP-A, 32.0\% PP-B and $18.0 \%$ PP-C.

\section{References}

Albuquerque, J. A. C. (2001). Planeta plástico: tudo que você precisa saber sobre plásticos. Porto Alegre: Sagra Luzzatto.

Bahlouli, N., Pessey, D., Raveyre, C., Guillet, J., Ahzi, S., Dahoun, A., \& Hiver, J. M. (2012). Recycling effects on the rheological and thermomechanical properties of polypropylene-based composites. Materials \& Design, 33, 451-458. http://dx.doi.org/10.1016/j.matdes.2011.04.049

Jansson, A., Möller, K., \& Gevert, T. (2003). Degradation of post-consumer polypropylene materials exposed to simulated recycling-mechanical properties. Polymer Degradation and Stability, 82(1), 37-46. http://dx.doi.org/10.1016/S0141-3910(03)00160-5

Junior, S. V. C. (2006). Ciência dos polímeros: um texto básico para tecnólogos e engenheiros (2 nd ed.). São Paulo: Artliber.

Mählmann, C. M., Rodriguez, A. L., Lopez, D. A. R., Niedersberg, C., Vaz, M. J., \& Teixeira, D. B. (2006). in: $17^{\circ}$ CBECIMat - Congresso Brasileiro de Engenharia e Ciência dos Materiais, Foz do Iguaçu.

Mano, E. B. (1991). Polímeros como Materiais de Engenharia. São Paulo: Edgard Blücher.

Matto, N. C. M., \& Peres, P. E. C. (2010). Coletar e reconhecer o plástico: uma atitude em educação ambiental (1st ed.).

Poulakis, J. G., \& Papaspyrides, C. D. (1997). Recycling of polypropylene by the dissolution/reprecipitation technique: I. A model study. Resources, Conservation and Recycling, 20(1), 31-41. http://dx.doi.org/10.1016/S0921-3449(97)01196-8 


\section{Copyrights}

Copyright for this article is retained by the author(s), with first publication rights granted to the journal.

This is an open-access article distributed under the terms and conditions of the Creative Commons Attribution license (http://creativecommons.org/licenses/by/3.0/). 